\title{
IMAGE CONSUMPTION OF PEOPLE PERCEIVED AS LEADERS
}

\author{
Julita Majczyk \\ University of Warsaw, Poland
}

\begin{abstract}
The purpose of this paper is to examine the way in which the press creates, sustains, and enhances a leader's legitimacy. The research subjects are not leaders considered as flesh-and-blood human beings, but rather the images of people perceived as leaders and their impact in the process of societal sensemaking. The paper addresses the role of the process of image construction and re-construction, as it then allows the individual to define what was noticed, categorize it within interpretative schemes, and understand reality as a distinct reflection of events. The image is studied using qualitative methods and techniques. The results indicate that although the literature on image management mostly emphasizes the role of impression management, the image of a leader is determined by social expectations. Therefore, the dynamics within the environment do not simply force the maintenance of the adapted perception of organizational identity, but rather the active management and development of identities throughout image process creation. Finally, it is argued the concept of a leader is masculinized and there is no universal scheme for building a leader's image.
\end{abstract}

Keywords: sensemaking, image management, framing

JEL code: D91, L82

\section{Introduction}

In the following study, the images of people perceived as leaders published in the Polish business press and their impact in the process of societal sensemaking are analyzed. Image plays distinct role in affecting receiver's perception (Kissel and Büttgen, 2015). A personalized image is a social creation process, and then consumption of images leads to establishment of the selves of social actors such as, for example, businesspeople. Prominent ones, who actively participate in the economic development of the environment by inspiring others to act, are often the subject of discussion and media interest. People who pursue professional activities and who are recognized for their good reputation are elevated from the general public into public figures, as they have a significant impact on the functioning of society (Ranft et al., 2006; Sanchez Abril, 2011). The ongoing process of globalization, the development of electronic communications, popularized advertising, and a growing interest in business have led to the situation in which leaders of organizations have been treated as celebrities ( Kjaergaard, Morsing and Ravasi, 2011; Morris, Brotheridge and Urbanski, 2005; Rindova, Pollock and Hayward, 2006; Sanchez Abril, 2011).

The process of image creation of a leader by the press has not yet been thoroughly examined 
(Chen and Meindl, 1991; Hannah and Zatzick, 2007; Hegele and Kieser, 2001). However, studying images between contemporary organizations and popular culture is not a nascent approach (Rehn, 2008; Tyler and Cohen, 2008). Image can be interpreted both as a way of perceiving leaders and presenting them (Jacquart and Antonakis, 2015). Building an image is an evolutionary, continuous process, adaptive in its nature, and designed to meet the expectations of the organizational environment. In the press, on television or the internet, published information is disseminated and can be based on recommendations of financial analysts, credit rating agencies, financial investors, industr or stock market investors. The audience of the communication channels absorbs the images created by the media. As a consequence, it has no authority to change it, however it is allowed to discuss the content of the message and to build their opinions and create their own image of the business entities (Anastasio, Rose and Chapman, 1999; Fombrun and Shanley, 1990). Following the thought of Baudrillard (2009), the media's role is to code events and reality instead of providing unprocessed material for individual sensemaking. Cultural artefacts, images, and representations have become part of the economic world (Connor, 1989), in which reality is replaced with the illusion of truth and, therefore, any simulation is no longer a reflection of reality (Baudrillard, 2009). According to Izak (2014: 369), this glamorized and re-contextualized image "is sifted through and mediated by feelings and experiences, until it becomes a more or less distant recollection of the thing it represents". Daily communication among people that comprises information exchange is one of the sources of image creation (Vásquez, Sergi and Cordelier, 2013). Each interview given, business ranking published in the press gives the audience an opportunity to analyze the image of a business leader through the lens of the media. The business leader image varies, as it depends on number of factors from the profile of a publishing house through a management fad to values shared in a given period of time. Thus, it can concentrate on personality traits, competencies, or only on certain achievements. The image building process is crucial for a company, as the way we perceive its leader determines how a company is perceived (Chen and Meindl, 1991). Thus, the focus of societal sensemaking on image is the starting point for the following examination. Just as social reality is an intersubjective construct of social actors (Berger and Luckmann, 1966), the image of a leader is the final result of the complex process of constructing and reconstructing that image both directly or indirectly by social actors related to the leader. Business leaders are ultimately the embodiment of the organizations they represent, and are described as the personification of characteristics and values of the organization (Chen and Meindl, 1991).

\section{Theoretical background}

A systematic literature review of the image concept allowed me to identify its impact on the audience and explain how it is designed. Image built by readers gives an answer to the question how they perceive the object (Hatch and Schultz, 2000, p. 23). It is a representation of someone's internal image of a particular object. Thus, it refers to its attributes. The image as the message itself aims to make the intended impression on the audience (Alvesson, 1990). It is an embodiment of a visible symbol, a concealed thought, silent assumption, or in other cases the effect of daily interaction within organization, or between people (Alvesson, 2001). 
Image is a concept associated with identity, reputation, and brand. Organizational identity is a reflection of images depicting the present (Gioia, Schultz and Corley, 2000). Identity gives an answer to the question of what we are as an organization. Reputation reflects what others think about the organization. A positive social image is the goal of conscious action of impression management behaviors (Sharma et al., 2006). The loss of a positive public image is known as reputational risk and may have serious, long-term effects on a subject's prosperity. The greatest threats to reputation are posed by a failure to comply with regulatory or legal obligations, poor service, poor quality of products offered, misbehavior, or misconduct. Brand refers to attributes that in our opinion are associated with the given product or services provided. Finally, whether it is (1) intentional or (2) constructed, the image answers the following questions: (1) in what way does the organization want others to think about it, or (2) what does the organization think that other think about it and what their associations with the organization are (Brown et al., 2006, p. 101). The terms given are of interest in numerous studies (Dutton, Dukerich and Harquail, 1994; Fombrun and Rindova, 2000; Gioia et al., 2000; Hatch and Schultz, 2000).

Self-image is partially conditioned by the belief of how an employee's organization is perceived by the environment. In order to maintain a positive self-image, an individual can act in a twofold manner: maintain a positive organizational image, and repair the negative one by choosing only those positive thoughts on the organization, thereby isolating tarnished images resulting from allegations of misconduct (Dutton et al., 1994). Sensemaking allows the individual to define what was noticed and categorize it within interpretative schemes. Making conclusions, giving a new meaning to objects leads to deepening social understanding (Weick, 1995). The meaning to reality is given retrospectively. As a result, individuals develop their own solutions for understanding past events and behaviors. The individual can change or adjust the meaning to reality given earlier if the negative images would disrupt self-enhancement or cohesion of one's own image (Weick, 1995).

The process of a leader's image creation has evolved with the concepts of leadership development. Eventually, celebrity leaders were born as a result of limited supervision of their actions and decision-making process. Such a transformation in controlling systems was dictated by the goal of achieving short term effectiveness and profits. Greater freedom for a leader in terms of management is justified by the need for organizational flexibility in turbulent and competitive markets, where the transition took place from a regulated to a deregulated environment and where the globalization process is advancing (Ranft, Ferris and Perryman, 2007). Marketing research shows that an image is the outcome of the interaction of media attention and its entertainment function, designed to support the sale of products perceived as stars. There are at least two reasons for maintaining the image. First, it attracts public attention. Second, it is considered an effect of fame earned through achievement and talent and therefore keeps the audience interested in and awaiting further potential successes (Ranft et al., 2006).

A manager represents and speaks for the organization (Mintzberg, 1973). Moreover, leaders are believed to be the personification of the business entity (Chen and Meindl, 1991). A 
person who earned the status of a celebrity leader has a positive impact on business efficiency and economic benefits (Davison, 2010; Wade et al., 2008). Organizational leaders perceived as celebrities are often considered superheroes. Not only have anecdotes been penned, and reports or articles written, but also books are published and movies made depicting various aspects of their lives. A prime example of this trend toward visibility is the growing popularity of individual business leaders such as Steve Jobs, Richard Branson, Paul Allen, Lee Iacocca, Liu Chuanzhi or Jack Welch. Presenting the leader as a person solely responsible for the financial condition of a company is favored over the person's characteristics, skills overview, or competencies. Thus, a leader-hero or a leader-celebrity can be distinguished on the basis of their media visibility (Morris et al., 2005).

To maintain a chosen image, a company creates its internal image directed at members of the organizational environment to provide them with a specific interpretative framework. However, the way this is used is an autonomous and individual decision by each image receiver. The individual who creates an image of a business entity uses data from various sources. Besides information obtained through social communication with its members, the audience uses press releases created and then disseminated by the organization, including statistics and business rankings. Corporate image is a holistic expression, a clear image of the organization, which in the specific social context gains in significance (Alvesson, 1990). Therefore, its image can reflect customers' perception of the business entity who have direct experience in the field or have a set of ideas about the entity (Mostafa et al., 2015). Although the internal image relates to the external image, they do differ (Fombrun and Shanley, 1990; Gioia et al., 2000). Members' beliefs about the perception of external parties are reflected in the external image (Dutton et al., 1994).

Various theoretical approaches can be applied to image analysis. The following theoretical perspectives are the result of a literature review carried out in the fields of organizational theory, communication, marketing, and public relations. According to social identity theory (Tajfel and Turner, 1979), people perceive themselves as members of various social groups. There is a tendency to identify oneself with similar individuals or subjects. Symbols and a sense of similarity characterizing those groups can enhance feelings of affiliation. Deepening self-identity can occur also by separating oneself from other social groups. And in order to boost self-image the individual can enhance the status of the group. Following this thread of a thought, it is stated that leaders have an influence on the identity creation process of members of their organizations (Avolio et al., 2009). Thus, a supervisor's attitude to daily routines can impact the way the employee perceives his/her relations with the organization, identifies $\mathrm{him} /$ herself with organizational tasks, or manifests behaviors under the sway of the specific leadership style adopted by the executive (Hongwei and Brown, 2013). Psychoanalysis contributes to the study of organizations, at least through exploration of subconscious mind (Freud, 1913/1955, Jung, 1921/1971), processes that cannot be parameterized and which shape our reactions to daily situations. Everything that is perceived and interpreted by us can contain elements of projected emotional bonds. A psychological reaction to a situation is meant to be an aspect of the social construction of reality. Constructed images reflecting internal struggles within the individual and limited trust to the environment determine both 
the decision-making process and the reactions of social actors (Jacobsen, 2013). From a symbolic interactionist perspective, (Goffman, 1959/2011; Mead,1938), each individual constructs self-images and social images which affect the perception of third parties. Self-image is the outcome of interaction with others, and communication takes place through exchanging meanings. This continuous process allows one to identify the way others perceive us and use the conclusions, beliefs, to construct our self-image. Thus, to achieve the intended impression, the individual is to play a role that fits best in the given context. Our perception is determined by a constructed self-image, personal beliefs about how an external audience perceives us, and own beliefs that the external image of us constructed by others actually exists (Petriglieri and Stein, 2012). However, personal beliefs referring to the external self-image can be misleading.

The above theoretical perspective review was to show the complexity of the image concept and to indicate that different approaches to image analysis, even though divergent, can be correct. In the following analysis, a social identity perspective was used. Each person can be interpreted in terms of specific social roles through the prism of social expectations, acting-out a particular social role in accordance with the perceived expectations of the individual, and the institutional context (Kostera, 1996). People play a variety of roles and to do this right they employ different tools, including a façade (Goffman, 1959/2011) - the social front that is constructed using physical scenery, attributes, or appearance. Analyzed objects - in the following study images of people perceived by the media as leaders - are seen as principal performers in the business environment. But is there any typical feature of the people perceived as leaders in the business field? What patterns are identified when constructing the image of a leader? Are there any? What lessons can be learnt from studying a business leader's image? To answer these questions, the focus of research is placed on irregularity and deviations in designing images and capturing objects of interest. In this case, the main language to be studied is body language. In order to interpret it correctly, each interpreter should set a norm for the identified object. Scholars create templates that follow the general guidelines for a norming technique (Reiman, 2009). As long as the interpreter is unable to recognize patterns in behavior of the explored object, it is advised to refer to what is perceived as the norm in a particular situation. Researches distinguish diverse forms of nonverbal communication (Arygle, 1994; Ekman \& Friesen, 1969, Ekman \& Friesen, 1967). This consists of mimicry, gesticulation, proxemics, and paralinguistic factors. The more aspects are established and identified, the more complete an image is received, and such an image is easier to interpret. In the following analysis, I referred to posture, facial expressions (eye contact, lips), hand gestures, attributes, and shot scenery when available. The role of non-verbal communication is undeniably important for sensemaking. Knowledge of or the ability to recognize natural gestures allows image and behavior to be tailored to achieve specific goals.

\section{Methods}

To understand legitimation over time, I studied images constructed by the press that depict people perceived as leaders. The material collected for the current study originates from the 
Polish business press. Particular attention is devoted to information that draws upon secondary data: "Profit", "Forbes: Profit", "Businessman.pl", and "Businessman Magazine" which is a pioneer of monthly macroeconomic issues on the Polish publishing market. I selected these for the following reasons. First, these magazines publish, or published, regular surveys - leader rankings - that listed individuals who own or run business and therefore have a major impact on the economic environment, its development, and further transition. Second, because of its elite reader profile that targets highly educated readers, including business executives and politicians, one can assume that magazines report on issues which are of public interest, regardless of the economic sector. Third, the availability of online historical archives or physical materials in at least one of two libraries - the University of Warsaw Library or the National Library of Poland - allowed me to carry out this study.

\subsection{Sampling photos}

I conducted the sampling from March to May 2016 by using library catalogues containing magazines that were published until 2015. I applied the keywords "business", "economics", and "magazine", expecting to find magazines on business issues. This initial search resulted in 11 periodicals for the period 1989-2015, regardless of the year when magazines were established.

I then conducted a further screening based on the following criteria. First, I selected those leader rankings comprising individuals and screened all press releases on whether or not they mentioned leaders in the field of economics or business with an impact on economic architecture. A major reduction was due to press materials which reported on enterprises or self-government units, or that lacked business rankings overall. The search resulted in a total of 35 leader rankings. I screened these for the presence of photos depicting people perceived as leaders. This examination resulted in 356 photos (343 individual portraits and 13 group photos for further in-depth analysis of the legitimation strategies). 356 photos depicted a total of 375 people. The portraits are comprised of images of 274 men and 101 women. The first photo of a business leader that I found was published in 1992, followed by six years of no single ranking list of businessmen.

\subsection{Analysis of empirical material}

The study used principles of a grounded theory approach for collecting and examining data in the business press. The inductive approach allows a more in-depth examination of particular social processes. As "qualitative study capitalizes on ordinary ways of getting acquainted with things" (Stake, 1995: 49), the study itself is thus based on a detailed investigation, with various kinds of data collected within their context. Following this thought, grounded theory research appears to be the best choice, as it allows an empirical investigation of leaders' images within its legitimation strategies context using documentary analysis.

Particular attention is devoted to the individual leader's activities, individuals perceived to be solely responsible for business development. In the study, the qualitative data are 
non-standardized and require classification into categories, as they are based on images, so the analysis is conducted through the use of conceptualization, critical and analytical thinking, although statistical techniques cannot be ruled out (Saunders, Lewis and Thornhill, 2003). This kind of evidence includes archival records, interviews, physical artifacts, and observations. Silverman (2000: 6) claims that "[...] qualitative research is influenced by the researcher's political values". To ensure content validity and to avoid a possible common source bias, data from four different magazines are used. Use of data from various magazines allows one to check if they point to the same facts. Moreover, different sources give a researcher confidence in drawing correct conclusions (Yin, 2009).

\section{The subject of interest}

The complexities of existing interpretations prompt leaders to analyze in detail what to show, and how, in order to construct a chosen image. Posing for photos, arrangement of portraits, attributes used by the photographed person help to interpret the image through the prism of the leader, his or her actions or attitude captured in the picture. Thus, the arrangement of photos is of strategic use. Firstly, it focuses on the leader, his or her appearance and the message the leader is supposed to convey. Secondly, it displays attributes that are supposed to define his or her position and social status.

The very first photo of a person claimed to be a business leader was taken in 1992. A man in a suit and tie with his hands on his lap, sitting in an armchair. In the background the basic attribute, a television set, of his basic business activity which is audiovisual equipment services. For the next six years there appears to be neither interest nor a business need in showing images of business leaders in the press. Only plain narratives, reviews on business galas or commentaries on recent business conferences. The continuous and ongoing business leader rankings trend started in 1999, and was started by rankings of female leaders. However, since 2006 female leaders disappeared from the Polish market, where in the business firmament the number of male leaders is increasing with each year that goes by.

The popularity of women was characterized by three factors. Firstly, women were visible in the business environment until 2005. After that date, one could say that they are unexpected guests in rankings, with two women listed. Secondly, images of female leaders are comparable with images of male leaders in terms of clothing suitable for formal social events such as participation in a business contest, the results of which are published nationwide. Thirdly, rankings were dedicated solely to women or to both men and women, whereas businessmen rankings were uncommon. The shift in the trend was dramatic and became apparent after 2006 - rankings became dominated by men.

\section{Power of framing shots}

Visual analysis of images of both women and men revealed that in the beginning of the process of creating images of business leaders, the photos accompanying narratives are constantly developed tools. Among the photos, I could identify portraits depicting a single 
person, portraits of a group of two to three people, and group photos showing all listed leaders in the given rankings. Single person portraits are essential, whereas group photos play a supporting role. They appear irregularly, and are shown in the very beginning or act as a ranking summary. They can be arranged together or be a photo collage presenting men and women, leaders who sit or stand, wear formal or less formal clothing, have their hands folded, arms crossed or present open position, face left or right, chat with each other or peacefully look at the camera. Group photos have the advantage of revealing the message of the leadership contest in a more symbolic way. The photographed persons may in one shot pretend to be rugby players, in another they are casino players in bow ties or ties, focused on the goal to win. Portraits of two or three persons are taken when the success of the company is significantly associated with the owners, usually friends or married couples.

Portraits dominate the scene in the the visualization of leaders. More than 93 percent of photos were dedicated to individual portraits. Throughout the time span under analysis, I could identify different types of framing shots. Among them are:

1. Wide shots that are used to introduce action, show the whole scene depicting the workplace, orientate the viewer.

2. Full shots that frame a silhouette, a person from head to toe, used to establish a character.

3. Three-quarter shot showing a person from the knees up.

4. Medium shot that frames a person from the waist up, often it allows for a closer view of the action or a character.

5. Head and shoulder shot depicting a person from the chest up used to provide a closer view of a character.

6. Head shots that show a person above the shoulders.

The beginning of the visualization of leaders gave close-up shots showing only the head of a character. After the first four years, the given framing shot made way for a medium shot. A person portrayed from the waist up dominates the scene of business leaders. Head and shoulder shots seem to be slightly less common than medium shots, but it is not clear whether it will ever replace the chest up frame. In the Polish press, there are specific rankings designed to show one type of framing shots of business leaders, while in others there is no simple visualizing pattern that could be inferred by the reader based on published images, as the given types of shots are easily interspersed. Within one list of business leaders, all six types of framing shots can be found, which makes the reader believe there was no clear concept of the publishing house to create a universal leader image template with a comprehensive set of criteria defining the business leader concept applicable to the business field and legitimized by press. The least popular framing shots comprise of full shots and three-quarter shots.

Photographs that are not popular, but which definitely have the ability to convey emotion, narrative, and messages on person's life are environmental photos. An environmental portrait tells a story about the leader (here, the main subject) and gives an insight into his/her world (the business world with the subject's responsibilities or successes) by capturing surroundings 
that add context to the shot. In such photos, the photographer has the opportunity to capture and depict the subject's character by showing the person in a situation they inhabit and a workplace that explains who they are, e. g. the owner of a pharmaceutical company wearing an iconic white coat and working in a lab, or the president of a radio station with headphones and a microphone, and eyes fixed on a task.

The shift is also visible in terms of image composition. In the beginning, only static images were published. Since 2005, dynamic images have been introduced and they result in a sense of movement and energy. The persons depicted tend to work, one is sketching a company, the other is grasping a charging bull by the horns. While the leader is shown in a static position, people around are expressing the motion - an audience applauding the person. In the background, the reader can notice an office full of people working. Dynamic composition seems diverse and interesting. Business leaders captured in a photograph that has impact look busy, as they have no time for entertainment.

\section{Designing the language}

Analysis of further elements was concentrated on the overall impression the photographed person makes, as the photographed persons depicted as business leaders pose. Sitting or standing with folded hands was their most salient mannerism. However, in 2011, this was dominated by the posture of arms crossed. Other identified gestures comprise hands resting comfortably on legs, clenched in raised or middle position, recently placed in the pockets, or pointing a finger at a reader which is done when imposing oneself, expressing confidence and authority. Two more gestures refer to chin and head gestures. Propping a chin or head up with hand seems to be a manner for business portraits. Gestures are used even though sometimes the person is ridiculous looking. Propping the chin up with hand used when listening to someone gave way in 2010 to propping the head with a hand. However, this sign of the communication can be understood in two ways - the person is bored or the person is thinking, even evaluating something. The information conveyed by such images is not obvious, and still too few photos are published to make conclusions on what aspects of social expectations trigger those specific gestures.

What distinguishes businesspeople, apart from the pose, is facial expression too. Leaders in the Polish press seem to celebrate their success with a smile, at least one third of them, both men and women, and the trend is rather constant. But again, there is no pattern how such people should smile - show their teeth or manifest a faint grin. While most of leaders are forward-facing, which gives the observer the uncanny feeling of being watched, the rest of them face left or right. Among all the analyzed portraits, only two persons faced downward and one was shown with head down, which could be easily interpreted as expression of a submissive attitude.

A dramatic change is visible in terms of the clothing shown in the images. Right from the beginning, both men and women were depicted as people in formal clothing. Tie and jackets were common elements of the business outfit. However, in 2013 a dramatic change is noticed 
that can be shortly summed up by loosening the requirements for a proper formal outfit. While attaching photos to a plain text become an integral part of an image building process, the growing popularity of attributes followed the trend, however they seem to be addressed inappropriate to business context sometimes. Attributes such as tie or jacket became a supplement where formality of a whole outfit gave way to casual look. And glasses are used as a hair accessory. Sunglasses do not reflect professionalism either, especially if they are used to prop someone's chin up with.

Photos of business leaders capture various objects associated with their offices, workplace or basic business activities. Other attributes comprise personal belongings that are supposed to be associated with their company's products. Recently, objects associated with a niche passion of leaders are included into image composition, however so far this works only for culture and the arts. Thus, in recent photos the observer can notice sculptures of people or body parts, or modern clocks situated in the company's buildings. Usually in the background there is only one visible attribute, often not easy to interpret as it is only partially shown. By studying portraits of leaders, the observer can notice a variety of attributes placed in the background there is no specific criteria for what to show, and what is better unpublished; however, all objects are to make associations and links between the leader and his responsibilities. Among them are a computer for the provision of software solutions for e-business and e-commerce, a wall of television sets or a satellite dish associated with television stations, a shot of a petrol station or newsstand, a world map associated with a travel company, an advertisement for a company or its products, a company's building, its logo or a logo of a successful investment, the value of a company according to the stock market seen in the listing room at the Warsaw Stock Exchange, the name of the institution with what the leader is supposed to sign a contract with, flagship products launched such as road vehicles, a chair, surgical lighting, or simply a poster of their products, machines used to provide services, or images of bottles referring to a distributor of spirit brands. There are also elements of clothing design creating an outfit and chosen in the sense of recognition of a certain style. Also listed could be the jackets, ties, bow-ties, pearls, and watches. Elements of clothing design are sometimes used to convey the company's profile. An amber necklace worn by one business leader was used to point out that the company's product creation is inspired by the material and that each product is marked with an amber eye as a proof of quality. However, they do not have to fit with work attire. Wearing a surgical mask, headphones or safety helmet worn by miners are captured in the photos to give the reader a better impression of the person's workplace. Making associations is done by capturing symbols of the services provided. The most distinct images depict a publisher with a newspaper, producers with their flagship products or semi-finished products, a fund transfer facilitator with credit cards, or a producer of mining machinery with a tool.

Sitting in a leather armchair or on chairs made of wood with curved legs and leather seats, showing watches or cufflinks was popular until 2008. Interior arrangement for offices captured on photos also changed - from a computer placed in the background through a wooden table, flowers, and objects of art to bookcases and a city view in the background. Elements shown in photos such as a city view, a skyscraper, holding a financial newspaper, or 
sitting in a racing car, can all be viewed by their nature as metaphorical, which gives a new insight into the topics. Skyscrapers serve as offices, commercial complexes, even residences that are the outcome of technological advancements. They are associated with a developing economy and financial districts. Holding a financial newspaper is associated with the audience described as the elite, comprising decision-makers in the political and corporate world and high net worth consumers. Following this thought, sitting in a racing car could symbolize the rising value of the fast-growing company, while holding binoculars manifest pinpointing the value of a product or service. The city view by its endless extent suggests a sense of infinite, the experience of dependency on the environment or otherwise, the power over other people, structures, or a system. But still probably the image of a carved armchair with leather covers is probably the most suggestive object symbolizing the power and authority of people showed in the Polish business press.

\section{Discussion and implications}

Leadership plays a symbolic role - it helps to understand events and behaviors of individuals. Referring to mythologies, fictional or real characters, historical figures characterized by the non-distinctive features who often achieve unreachable goals, make the leadership theme even more attractive (March and Weil, 2005). Images of managers, business leaders, and chief executives are considered to be a significant element in the process of image construction of the organizational identity. Interviews, business articles, and photographs of leaders are used to legitimize business entities and enhance authenticity. Authenticity that is grounded in attractive leader images creates trust in turn (Weischer, Weibler and Petersen, 2013). Thus, portraits and photographs of business leaders have become an integral part of the social construction of business leadership (Guthey and Jackson, 2005). They are used as another tool for building someone's social position in which non-verbal communication plays an important role while the image is being reconstructed by observers. Facial expressions provide additional information that help build interpretative schemes. Unless a photographed person faces down, a submissive attitude is not expressed. Even eyebrows and lips express the given individuality, however eyebrows, rather than lips, can be considered in terms of a domination rate and empowerment indicator (Keating, Mazur and Segall, 1977). If the person smiles, the more cordial and sociable s/he seems to be.

Journalists are expected to conform to standards of impartiality, reliability, and objectivity when disseminating information (Hayward, Rindova and Pollock, 2004). However, the created image is the result of individual decisions of people responsible for broadcasting news. The presentation of selected and tailored information impacts public opinion and shapes its perception of events ( Deephouse, 2000; Westphal and Deephouse, 2011). To make it easier for the audience to interpret images, they are accompanied by descriptive texts. Photos that supplement financial documentation are in this case just another element that confirms the accuracy and veracity of financial statements. And photographs showing business leaders seem to support the view of the direction of the company's development (Davison, 2010). A business leader perceived as a person solely responsible for the organization's condition who has a tendency to sacrifice him/herself to achieve ambitious goals and simultaneously acquire 
confidence in mastering challenges and operations, allows situations to arise in which the leader is recognized as business icon but his/her image could be already just a distant recollection of what was the reality.

Studies have shown that mental representations of leaders have become so widespread that respondents believe they are able to assess someone's leadership potential using facial image only. Little (2014) proved that manipulation of eye distance influences the perception of competencies. According to these findings, respondents are also able to assign specific tasks to people who in their opinion are more likely to do it effectively. Another study (Olivola, Eubanks and Lovelace, 2014) indicated that already the facial contour (other elements visible in the photographs such as background, ears, neck, hair) provides enough information for observers to help them decide who of those photographed are business leaders. On the basis of photographs, respondents assessed sports leaders and military ones as masculine and mature, but less competent than leaders in politics or business who are perceived as more attractive and cordial.

However, the perception of leaders is culturally conditioned. A study of American students asked to assess the appearance, personality, and effectiveness of 71 CEOs of Chinese companies listed on the Hong Kong Stock Exchange showed that use of Western interpretative leadership schemes is misleading. Facial images appeared to provide incomplete information valid for the personality assessment. Domination, trust, or charisma that characterize Western leaders is not applicable in Asian culture (Harms, Han and Chen, 2012). The leader-follower relationship is influenced also by the perception of gender. A study of 40 photographs of business executives listed on the Fortune 1000 proved that men and women are assigned specific personality traits. Male leaders are associated with such qualities as domination, leadership competencies, and power, while women are expected to be compassionate, cordial, and provide support to fellow employees. Compassion, cordiality and supportive behavior in terms of female business executives can influence organizational profits, company's ranking, or the female leader's position, while it is power for male leaders. The physical attractiveness of male leaders increased with a better evaluation of personality traits, while the perception of attractiveness was based on the assessment of femininity for women (Pillemer, Graham and Burke, 2014). The results of the study clearly point to a stereotypical approach to evaluation of leaders, in which gender differentiation allows stakeholders to make sense both of leadership and leaders. But it also relies on another set of variables used in the research. Studies conducted in German high schools on pupils from the age of 14 through 17 confirmed that regardless of sex, generally the higher facial index, the more positive impressions are implied. According to data, in the photographs of people perceived as more assertive, ambitious, intelligent, and decisive, the person's face was included, not the entire image. High school students admitted that people whose portraits show the image of the head have enhanced professional competence (Schwarz and Kurz, 1989). The facial index is influenced by socio-demographic characteristics. Analysis of nineteenth and early twentieth century American art objects, collection of stamps, 640 photographs published in American periodicals such as "Life", "Time", "U.S. News and World Report", "Newsweek", and 240 photographs found in European periodicals "Illustrated 
London News" (United Kingdom), "Le Nouvel Observateur" (France), "Der Spiegel" (Germany), "Cambio 16" (Spain), confirmed significant differences in factors related to race, sex, and geography (Zuckerman and Kieffer, 1994). Dominant characters are typically represented by white men regardless of geographical areas. However, the results of the analysis outlined above apply to professional photographers. There is no confirmation of significance of the facial index in amateur images. That may be due to lack of knowledge or limited knowledge on content manipulation via selecting and tailoring information. However, images of leaders in the Polish press are dominated recently by medium shots, reversing a trend. Such image composition allows more objects to be captured that could leave leader's imprint in the social space and still go in line with the contextual strategy selected by the social actor. Information conveyed in the published image allows initiation of the social mediation process by the audience who starts to be the active constructor of the business world, in which leaders are supposed to be supported by artefacts legitimizing their position.

While studying images of businesspeople regardless of the narratives, the audience could face problems with interpreting the conveyed information. Some attributes, often partially shown, are hard to identify, even if the reader is acquainted with the leader's background. Photos of men with hands in their pockets are growing considerably more common. Women in the business world have recently become invisible. Undeniably, image construction has changed; however, there seem to be no universal criteria that could be adopted for building a leader's image. Knowledge of body language, like folding hands properly or holding one's head to look prominent, decisive, and confident, is developed but the problem is with implementation. Thus, it sometimes takes a while to acknowledge a ridiculous pose captured in the photo. Image reconstruction is a continuous process in transition. It is definitely under constant development that allows experimentation. Referring to the findings, the audience in the given time should face images depicting artefacts that symbolize empowerment, independence of action and freedom of choice, or personal passion for art.

\section{Conclusions}

The study has some limitations. First, I analyzed journalistic materials, but there are other sources of data that could be explored. Narratives or interviews with photographers, press or public relations officers would shed light on the process of image construction as sensemaking. Audience opinion would facilitate also my understanding of how readers interpret images of businesspeople. Second, given the nature of the data gathered, I am unable to describe the interaction between cognition and further action.

To conclude, the image of a leader is determined by social expectations. The dynamics within the environment force not simply the maintenance of the adopted perception of organizational identity, but active management and development of identities also through image process creation, in which the external image is created by both members of the organization, and the social actors from outside (Gioia et al., 2000). It is important to manage the image both inside and outside the organization as it could influence the market position of the company or the leader itself. By building leaders' images, the media contribute to the process of sensemaking 
of the organizations. The media share its reinterpretation of successful businesspeople, thus participate in continuing leaders' legitimacy.

\section{References}

Alvesson, M. (1990) “Organization: From Substance to Image?”, Organization Studies, vol. 11, no. 3, pp. 373-394. doi:10.1177/017084069001100303

Alvesson, M. (2001) "Knowledge Work: Ambiguity, Image and Identity", Human Relations, vol. 54, no. 7, pp. 863-886. doi:10.1177/0018726701547004

Anastasio, P. A., Rose, K. C. \& Chapman, J. (1999) "Can the Media Create Public Opinion? A Social-Identity Approach", Current Directions in Psychological Science, vol. 8, no. 5, pp. 152-155. doi: 10.1111/1467-8721.00036.

Arygle, M. (1994) The Psychology of Interpersonal Behaviour, $5^{\text {th }}$ edn, London: Penguin Books.

Avolio, B., Walumbwa, F. \& Weber, T. J. (2009) "Leadership: Current theories, research, and future directions", Annual Review of Psychology, vol. 60, pp. 421-449. doi:10.1146/annurev.psych.60.110707.163621

Baudrillard, J. (2009) "The precession of simulacra" in Storey, J. (ed.) Cultural Theory and Popular Culture: A Reader, $4^{\text {th }}$ edn, Harlow: Pearson Education.

Berger, P. L. \& Luckmann, T. (1966) The social construction of reality: a treatise in the sociology of knowledge, New York: Anchor Books.

Brown, T. J., Dacin, P. A., Pratt, M. G. \& Whetten, D. A. (2006) "Identity, Intended Image, Construed Image, and Reputation: An Interdisciplinary Framework and Suggested Terminology", Journal of the Academy of Marketing Science, vol. 34, no. 2, pp. 99-106. doi:10.1177/0092070305284969

Chen, C. C. \& Meindl, J. R. (1991) "The Construction of Leadership Images in the Popular Press: The Case of Donald Burr and People Express", Administrative Science Quarterly, vol. 36 , no. 4, pp. 521-551.

Connor, S. (1989) Postmodernist Culture: An Introduction to Theories of the Contemporary, Oxford: Blackwell.

Davison, J. (2010) "[In]visible [in]tangibles: Visual portraits of the business élite", Accounting, Organizations and Society, vol. 35, no. 2, pp. 165-183. doi: 10.1016/j.aos.2009.03.003. 
Deephouse, D. L. (2000) "Media Reputation as a Strategic Resource: An Integration of Mass Communication and Resource-Based Theories", Journal of Management, vol. 26, no. 6, pp. 1091-1112. doi: 10.1177/014920630002600602.

Dutton, J. E., Dukerich, J. M. \& Harquail, C. V. (1994) "Organizational images and member identification", Administrative Science Quarterly, vol. 39, no. 2, pp. 239-263. doi: $10.2307 / 2393235$

Ekman, P. \& Friesen, W.V. (1967) "Head and body cues in the judgment of emotion: a reformulation”, Perceptual and Motor Skills, vol. 24, pp. 711-724.

Ekman, P. \& Friesen, W.V. (1969) "The repertoire of nonverbal behavior: categories, origins, usage, and coding", Semiotica, vol. 1, no. 1, pp. 49-98.

Fombrun, C. \& Shanley, M. (1990) "What's in a name? Reputation building and corporate strategy", Academy of Management Journal, vol. 33, no. 2, pp. 233-258.

Fombrun, C. J. \& Rindova, V. P. (2000) "The road to transparency: Reputation management at Royal Dutch/Shell”, in Schultz, M., Hatch, M. J. and Larsen, M. H. (ed.) The expressive organization: Linking identity, reputation, and the corporate brand, Oxford: Oxford University Press.

Freud, S. (1913/1955) "The claims of psychoanalysis to scientific interest”, in Strachey, J. (ed.) The Standard Edition of the Complete Psychological Works of Sigmund Freud, Volume XIII (1913-1914): Totem and Taboo and Other Works, London: Hogarth.

Gioia, D. A., Schultz, M. \& Corley, K. G. (2000) "Organizational Identity, Image, and Adaptive Instability", The Academy of Management Review, vol. 25, no. 1, pp. 63-81.

Goffman, E. (1959/2011) Człowiek w teatrze życia codziennego, Warszawa: Aletheia.

Guthey, E. \& Jackson, B. (2005) "CEO Portraits and the Authenticity Paradox", Journal of Management Studies, vol. 42, no. 5, pp. 1057-1082. doi: 10.1111/j.1467-6486.2005.00532.x.

Hannah, D. R. \& Zatzick, C. D. (2007) "An Examination of Leader Portrayals in the U.S. Business Press Following the Landmark Scandals of the Early 21st Century", Journal of Business Ethics, vol. 79, no. 4, pp. 361-377. doi: 10.1007/s10551-007-9406-4.

Harms, P. D., Han, G. \& Chen, H. (2012) "Recognizing Leadership at a Distance: A Study of Leader Effectiveness Across Cultures”, Journal of Leadership \& Organizational Studies, vol. 19, no. 2, pp. 164-172. doi: 10.1177/1548051812436812.

Hatch, M. J., 7 Schultz, M. (2000) "Scaling the Tower of Babel: Relational differences between identity, image, and culture in organizations", in Schultz, M., Hatch, M. J. and Larsen, M. H. 
(ed.) The expressive organization: Linking identity, reputation, and the corporate brand, Oxford: Oxford University Press.

Hayward, M. L. A., Rindova, V. P. \& Pollock, T. G. (2004) "Believing one's own press: The causes and consequences of CEO celebrity", Strategic Management Journal, vol. 25, no. 7, pp. 637-653. doi: 10.1002/smj.405.

Hegele, C. \& Kieser, A. (2001) "Control the Construction of Your Legend or Someone Else Will: An Analysis of Texts on Jack Welch”, Journal of Management Inquiry, vol. 10, no. 4, pp. 298-309.

Hongwei, H. \& Brown, A. D. (2013) “Organizational Identity and Organizational Identification: A Review of the Literature and Suggestions for Future Research", Group \& Organization Management, vol. 38, no. 1, pp. 3-35. doi:10.1177/1059601112473815

Izak, M. (2014) "Translucent society and its non-fortuitous design: Producing and consuming reality through images", Culture and Organization, vol. 20, no. 5, pp. 359-376. doi: 10.1080/14759551.2014.950659.

Jacobsen, K. (2013) "Why Freud matters: Psychoanalysis and international relations revisited", International Relations, vol. 27, no. 4, pp. 393-416. doi:10.1177/0047117813492448

Jacquart, P. \& Antonakis, J. (2015) "When does charisma matter for top-level leaders? Effect of attributional ambiguity”, Academy of Management Journal, vol. 58, no. 4, pp. 1051-1074.

Jung, C. G. (1921/1971) "Psychological Types", in Adler, G. and Hull, R. F. C. (ed.) The Collected Works of C. G. Jung, vol. 6, Princeton: Princeton University Press.

Keating, C. F., Mazur, A. \& Segall, M. H. (1977) "Facial Gestures Which Influence the Perception of Status", Sociometry, vol. 40, no. 4, pp. 374-378.

Kissel, P. \& Büttgen, M. J. (2015) "Using social media to communicate employer brand identity: The impact on corporate image and employer attractiveness", Journal of Brand Management, vol. 22, pp. 755-777. doi:10.1057/bm.2015.42

Kjaergaard, A., Morsing, M. \& Ravasi, D. (2011) "Mediating Identity: A Study of Media Influence on Organizational Identity Construction in a Celebrity Firm", Journal of Management Studies, vol. 48, no. 3, pp. 514-543. doi: 10.1111/j.1467-6486.2010.00954.x.

Kostera, M. (1996) Postmodernizm w zarzadzaniu, Warszawa: PWE.

Little, A. C. (2014) "Facial appearance and leader choice in different contexts: Evidence for task contingent selection based on implicit and learned face-behaviour/face-ability 
associations", The Leadership Quarterly, vol. 25, no. 5, pp. 865-874. doi:10.1016/j.leaqua.2014.04.002

March, J. G. \& Weil, T. (2005) On leadership, Oxford: Blackwell Publishing.

Mead, G. H. (1938) Philosophy of the act, Chicago, IL: University of Chicago Press.

Mintzberg, H. (1973) The Nature of Managerial Work, New York: Harper \& Row.

Morris, J. A., Brotheridge, C. M. \& Urbanski, J. C. (2005) "Bringing humility to leadership: Antecedents and consequences of leader humility", Human Relations, vol. 58, no. 10, pp. 1323-1350. doi: 10.1177/0018726705059929.

Mostafa, R. B., Lages, C. R., Shabbir, H. A. \& Thwaites, D. (2015) "Corporate Image: A Service Recovery Perspective”, Journal of Service Research, vol. 18, no. 4, pp. 468-483. doi:10.1177/1094670515584146

Olivola, C. Y., Eubanks, D. L. \& Lovelace, J. B. (2014) "The many (distinctive) faces of leadership: Inferring leadership domain from facial appearance", The Leadership Quarterly, vol. 25, no. 5, pp. 817-834. doi: 10.1016/j.leaqua.2014.06.002.

Petriglieri, G. \& Stein, M. (2012) "The Unwanted Self: Projective Identification in Leaders' Identity Work", Organization Studies, vol. 33, no. 9, pp. 1217-1235. doi:10.1177/0170840612448158

Pillemer, J., Graham, E. R. and Burke, D. M. (2014) “The face says it all: CEOs, gender, and predicting corporate performance”, The Leadership Quarterly, vol. 25, no. 5, pp. 855-864. doi: 10.1016/j.leaqua.2014.07.002.

Ranft, A. L., Ferris, G. R. and Perryman, A. A. (2007) "Dealing with Celebrity and Accountability in the Top Job", Human Resource Management, vol. 46, no. 4, pp. 671-682. doi: $10.1002 / \mathrm{hrm}$.

Ranft, A. L., Zinko, R., Ferris, G. R. and Buckley, M. R. (2006) "Marketing the Image of Management: The Costs and Benefits of CEO Reputation", Organizational Dynamics, vol. 35, no. 3, pp. 279-290. doi: 10.1016/j.orgdyn.2006.05.003.

Rehn, A. (2008) "Pop (Culture) Goes the Organization: On Highbrow, Lowbrow and Hybrids in Studying Popular Culture Within Organization Studies”, Organization, vol. 15, no. 5, pp. 765-783. doi: 10.1177/1350508408093652.

Reiman, T. (2009) The Power of Body Language, New York: Pocket Books. 
Rindova, V. P., Pollock, T. G. \& Hayward, M. L. A. (2006) "Celebrity Firms: The Social Construction of Market Popularity", The Academy of Management Review, vol. 31, no. 1, pp. $50-71$.

Sanchez Abril, P. (2011) “The Evolution of Business Celebrity in American Law and Society”, American Business Law Journal, vol. 48, no. 2, pp. 177-225.

Saunders, M., Lewis, P. \& Thornhill, A. (2003) Research Methods for Business Students, $3^{\text {rd }}$ edn, London: Financial Times Prentice Hall.

Schwarz, N. \& Kurz, E. (1989) "What's in a picture? The impact of face-ism on trait attribution”, European Journal of Social Psychology, vol. 19, no. 4, pp. 311-316.

Sharma, D., Albers-Miller, N. D., Pelton, L. E. \& Straughan, R. D. (2006) “The Impact of Image Management, Self-Justification, and Escalation of Commitment on Knowledge Development in the Marketing Discipline", Journal of Marketing Education, vol. 28, no. 2, pp. 161-171. doi: $10.1177 / 0273475306288659$.

Silverman, D. (2011) Interpreting Qualitative Data, $4^{\text {th }}$ edn, London - Thousand Oaks - New Delhi - Singapore: Sage Publications.

Stake, R. (1995) The art of case research, London: Sage Publications.

Tajfel, H. \& Turner, J. C. (1979) “An integrative theory of intergroup conflict”, in Austin, W. G. and Worchel, S. (ed.) The Social Psychology of Intergroup Relations, Monterey, CA: Brooks/ Cole.

Tyler, M. \& Cohen, L. (2008) "Management in/as Comic Relief: Queer Theory and Gender Performativity in The Office", Gender,Work and Organization, vol. 15, no. 2, pp. 113-132. doi: 10.1111/j.1468-0432.2007.00351.x.

Vásquez, C., Sergi, V. \& Cordelier, B. (2013) "From being branded to doing branding: Studying representation practices from a communication-centered approach", Scandinavian Journal of Management, vol. 29, no. 2, pp. 135-146. doi: 10.1016/j.scaman.2013.02.002.

Wade, J. B., Porac, J. F., Pollock, T. G. \& Graffin, S. D. (2008) "Star CEOs. Benefit or burden?", Organizational Dynamics, vol. 37, no. 2, pp. 203-210. doi: 10.1016/j.orgdyn.2008.02.007.

Weick, K. E. (1995) Sensemaking in organizations, Thousand Oaks: Sage Publications.

Weischer, A. E., Weibler, J. \& Petersen, M. (2013) “"To thine own self be true': The effects of enactment and life storytelling on perceived leader authenticity", The Leadership Quarterly, vol. 24, no. 4, pp. 477-495. doi: 10.1016/j.leaqua.2013.03.003. 
Westphal, J. D. \& Deephouse, D. L. (2011) “Avoiding Bad Press: Interpersonal Influence in Relations Between CEOs and Journalists and the Consequences for Press Reporting About Firms and Their Leadership", Organization Science, vol. 22, no. 4, pp. 1061-1086. doi: 10.1287/orsc. 1100.0563 .

Yin, R. K. (2009) Case study research: design and methods, $4^{\text {th }}$ edn, London: Sage Publications.

Zuckerman, M. \& Kieffer, S. C. (1994) "Race Differences in Face-ism: Does Facial Prominence Imply Dominance?”, Journal of Personality and Social Psychology, vol. 66, no. 1, pp. 86-92. doi: 10.1037//0022-3514.66.1.86. 